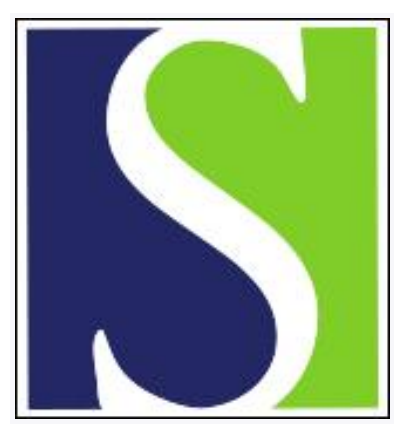

Scand J Work Environ Health 1987;13(4):348-351

https://doi.org/10.5271/sjweh.2044

Issue date: Aug 1987

Finger thermometry in the assessment of subjects with vibration-induced white finger.

by Bovenzi $\mathrm{M}$

Affiliation: Institute of Occupational Health, University of Trieste, Italy.

This article in PubMed: www.ncbi.nlm.nih.gov/pubmed/3324314

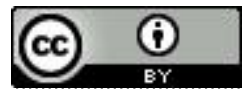




\title{
Finger thermometry in the assessment of subjects with vibration-induced white finger
}

\author{
by Massimo Bovenzi, MD ${ }^{1}$
}

\begin{abstract}
BOVENZI M. Finger thermometry in the assessment of subjects with vibration-induced white finger. Scand $J$ Work Environ Health 13 (1987) 348-351. The measurement of finger skin temperature (FST) is one of the most commonly used methods for evaluating the response of the digital vessels to cold stimulation. In well-controlled experiments a significant correlation has been observed between FST and digital blood flow over a wide range of water temperatures. On the contrary, FST in air is considered an inadequate index of digital skin circulation since, at a given ambient temperature, FST depends not only on the rate of blood flow through the digit but also on environmental conditions. Despite these limitations, FST recording after a cooling procedure has been used in surveys of vibration-induced white finger (VWF), and a delayed finger rewarming time has been proposed as an indicator of digital vasospasm in workers with VWF. Finger skin thermometry can differentiate between VWF groups and healthy groups, but it is unsuitable for diagnosing Raynaud's phenomenon on an individual basis. The thermometric method has good specificity but its sensitivity is lower than that of plethysmographic techniques. FST after cold provocation may be considered a useful screening test in field studies, while more sensitive methods should be employed to confirm VWF symptoms in individuals objectively, especially for insurance compensation purposes.
\end{abstract}

Key terms: cold provocation test, digital circulation, finger rewarming, finger skin temperature, recovery time.

Many objective tests have been developed to detect circulatory impairment in the fingers of vibration-exposed workers, but at present none of the proposed tests seems to be completely satisfactory. In vascular laboratories plethysmographic, Doppler ultrasound, and radioisotope clearance methods are used for recording digital blood pressure and flow, while infrared thermography is employed to study in detail skin surface temperature distributions over the hands and the fingers. These techniques have, however, the disadvantages of being expensive and time-consuming. Surveys of vibration-exposed workers are frequently carried out in the field, where detecting digital vasospastic disorders requires simple objective tests such as visual inspection of skin color and finger skin thermometry after cold provocation.

\section{Skin temperature and blood flow in the human finger}

Finger skin temperature (FST) is considered a useful physiological parameter for evaluating the response of the digital vessels to cold stimulation. The use of the thermometric method to assess peripheral vascular reactivity is based upon the assumption that FST depends

\footnotetext{
1 Institute of Occupational Health, University of Trieste, Trieste, Italy.
}

Reprint requests to: Dr M Bovenzi, Istituto di Medicina del Lavoro, Università di Trieste, c/o Centro Tumori, Via della Pietà, 19, I-34129 Trieste, Italy. on the rate of blood flow through the digit. Nevertheless there exists experimental evidence that this assumption is valid only under standardized laboratory conditions. Hsieh et al (5) observed a highly significant correlation between FST and blood flow in the fingertips of nine volunteers whose fingers were immersed for $20 \mathrm{~min}$ in slowly stirred water at various temperatures (range $4.6^{\circ} \mathrm{C}-40^{\circ} \mathrm{C}$ ), minimum blood flow through the fingertip occurring at about $10^{\circ} \mathrm{C}$.

Montgomery (7) reviewed 20 reports on quantitative determinations of human hand and finger blood flow as functions of skin and room temperatures. At a skin temperature of about $20^{\circ} \mathrm{C}$, maximum vasoconstriction took place in the hand and digital vessels, and below $20^{\circ} \mathrm{C}$ cold vasodilatation could be observed. Above $20^{\circ} \mathrm{C}$ blood flow increased, and at progressively higher temperatures the rate of increase plotted graphically displayed a rising slope tending to become vertical between 33 and $40^{\circ} \mathrm{C}$. Skin temperature of the hands plays a prominent role in the regulation of heat exchange between the human body and its environment. At a given ambient temperature FST is determined by the complex interaction of several physiological and physical variables so that its relationship to blood flow differs from that observed in the aforementioned experimental studies. According to Greenfield (4) FST in air is an imperfect index of digital blood flow because FST depends not only on the amount of blood passing through the digit but also on environmental parameters such as air temperature, mean radiant temperature, relative air velocity, and humidity. Despite these limitations, the monitoring of 
FST after cold stress can be used in surveys of vibration-induced white finger (VWF), in studies on human reaction to cold, and in the evaluation of the effectiveness of medical treatment in patients with Raynaud's phenomenon.

\section{Finger skin temperature and the cold provoca- tion test in studies of vibration-induced white finger}

Digital temperatures are usually measured by thermistors or thermocouples attached to the skin surface of the fingers. Montgomery \& Williams (8) reported detailed thermal profiles of the forearms, hands, and fingers of seven resting male subjects exposed to cold $\left(9.8^{\circ} \mathrm{C}\right)$, neutral $\left(23.4^{\circ} \mathrm{C}\right)$, and warm $\left(46.8^{\circ} \mathrm{C}\right)$ ambient temperatures. No differences between the right and left sides of the upper extremities were observed at each ambient temperature. These results are consistent with other findings in a field survey comprising 169 vibration-exposed shipyard caulkers and 60 referents (1). Within each group no asymmetry between the resting skin temperatures of the right and left hands and fingers was noticed, whereas significant differences were found between the two groups at every measurement location (figure 1). It is noteworthy that, in two investigations, finger blood pressure and flow were found to be lower in a group of granite quarrymen (10) and in a group of chain sawyers (9) than in their corresponding reference group; these findings indicate that, among vibration-exposed workers, digital blood perfusion may be reduced even at rest.

To provoke digital vasospastic attacks, several cooling procedures have been described for the hands with different water temperatures and immersion times. It is believed that the pattern of FST following the cooling period reflects, to a large extent, the degree of cold-induced vasoconstriction in the digital vessels. As a result, the delayed recovery time of FST is considered a useful indicator of persistent digital vasospasm. It should be remembered, however, that, in addition to the environmental conditions previously mentioned, even individual variables such as age, anthropometric parameters, emotional state, and cigarette smoking $(2,11,13)$ have been found to influence finger rewarming time after cold provocation. It has been suggested that the rewarming time of fingertips to ambient temperature after combined ischemia and cooling of the hands is a sensitive test to assess digital vasospasm (6). My co-workers and I have applied this test to a group of 76 vibration-exposed travertine quarrymen and to a group of 56 unexposed subjects working at the same quarries. The mean rewarming time to room temperature $\left(21^{\circ} \mathrm{C}\right)$ was more prolonged among the 27 travertine operators with VWF [7.5 (SD 7.9) $\mathrm{min}$ ] than among those without VWF [2.8 (SD 2.3) $\mathrm{min}]$ and the referents [2.8 (SD 2.2) $\mathrm{min}](\mathrm{P}<0.001)$. Our data showed that the rewarming time discrimi-
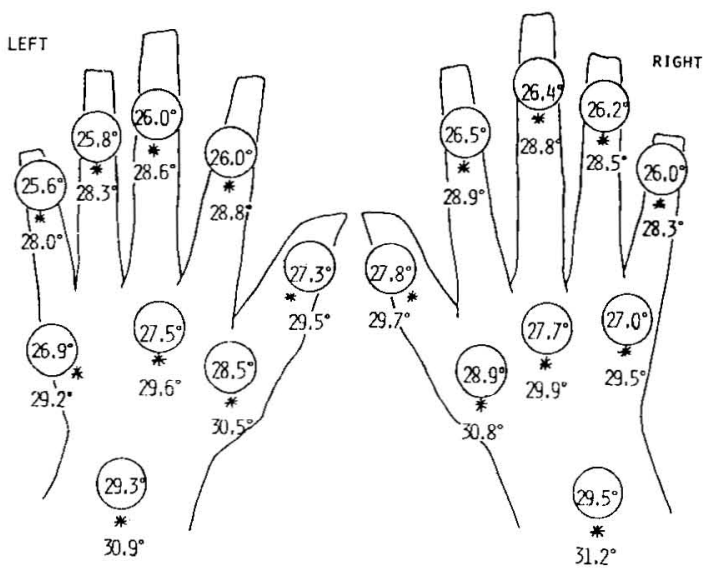

Figure 1. Mean skin temperatures recorded on the dorsal side of the fingers and the hands of 169 vibration-exposed shipyard caulkers (circled values) and of 60 reference workers under resting conditions (room temperature $21^{\circ} \mathrm{C}$ ). Asterisks indicate the thermistor locations on the skin surface. The differences in skin temperatures between the caulkers and the referents were highly significant at each measurement location $(P<0.001)$.

nated between affected and nonaffected worker groups, but did not discriminate between individual cases because of the negative test results observed for some subjects with a positive history of VWF.

The recovery time of the baseline FST after cold exposure is another important parameter for evaluating indirectly the changes in skin blood flow resulting from the release of cold-induced digital vasospasm. The upper normal limit for the recovery time is difficult to define as it depends on the water temperature and on the immersion time. Porter et al (12) found that, among 30 normal subjects, the recovery time after hand immersion in an ice-water mixture for $20 \mathrm{~s}$ averaged 10 (range 5-20) min. Cleophas et al (3) reported that healthy subjects recovered their FST within $12 \mathrm{~min}$ after finger cooling in water at $16^{\circ} \mathrm{C}$ for $5 \mathrm{~min}$. Chucker et al (2) observed that $78.4 \%$ of 51 normals showed thermograms of complete recovery during the first $20 \mathrm{~min}$ following the immersion of both hands in ice water for $1 \mathrm{~min}$. In a recent laboratory investigation I have measured FST and digital blood pressure after combined body and local cooling in 84 vibration-exposed workers using chipping, riveting and grinding tools and in 26 comparable reference workers. The subjects equilibrated for $30 \mathrm{~min}$ at a room temperature of $22-24^{\circ} \mathrm{C}$, and then baseline measurements were taken. After the cold provocation (immersion of one finger in ice water at $5^{\circ} \mathrm{C}$ for 5 min during ischemia), finger systolic pressure (FSP) was recorded and the percentage of change in the resting digital blood pressure (FSP \%) was calculated (10). The FST was continuously monitored before, during, and after the cooling procedure by a thermistor probe (figure 2). The mean FST values from the 4th to the 30th minute after the removal of the finger from the cold water were significantly lower for the 


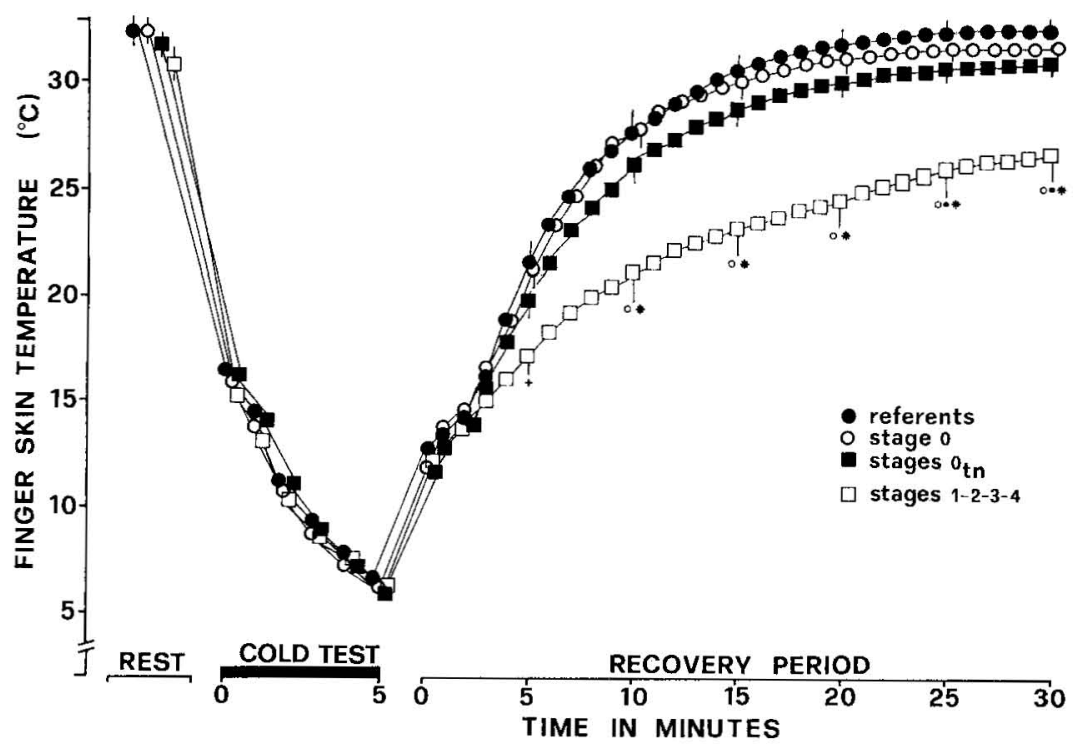

Figure 2. Mean finger skin temperatures measured before, during, and after local cooling and ischemia in reference subjects $(\mathrm{N}=26)$ and in vibration-exposed workers with no symptoms (stage $0, N=28$ ) or with neurological disturbances (stages $0_{\mathrm{TN}}, \mathrm{N}=36$ ) or with vibration-induced white finger (stages 1, 2, 3 \& 4 $N=20$ ). Vertical bars represent standard errors of the means (significant from referents: $+P<0.01,{ }^{*} P<0.001$, significant from stage $0:+P<$ $0.01, \cdot P<0.005,{ }^{*} P<0.001$, significant from stages $0_{T N}$ : - $P<0.005$ )

Table 1. Sensitivity and specificity of different objective criteria for diagnosing vibration-induced white finger (VWF) with cold provocation (immersion of one finger in ice water at $5^{\circ} \mathrm{C}$ for $5 \mathrm{~min}$ during ischemia). (FST $=$ finger skin temperature, FSP $\%$ = finger systolic pressure after local cooiing, expressed as the percentage of the base-line digital blood pressure)

\begin{tabular}{ccccc}
\hline & \multicolumn{2}{c}{ Vibration- } & & \\
exposed workers & Sensi- & $\begin{array}{c}\text { Speci- } \\
\text { Diagnostic criteria }\end{array}$ \\
\cline { 2 - 3 } & $\begin{array}{c}\text { With } \\
\text { VWF Without }\end{array}$ & $\begin{array}{c}\text { tivity } \\
\text { ficity }\end{array}$ & $(\%)$ & $(\%)$ \\
& $(N=20)$ & $(N=64)$ & & \\
\hline
\end{tabular}

Percentage of recovery of

basal FST: $<86 \%$ at

20 min after local cooling ${ }^{3}$

Positive

Negative

Zero blood pressure in the

finger after local cooling

Positive

Negative

FSP\%: $<60 \%$ after local

cooling ${ }^{a}$

Positive

Negative

12
8

5

60

92

$\begin{array}{rrrr}14 & 2 & 70 & 97\end{array}$

a Lower normal timits (mean $-2 \mathrm{SD}$ ) from 26 referents.

vibration-exposed workers with VWF (stages 1, 2, 3 and 4 of Taylor's classification) than in the referents and in the other vibration workers with no symptoms (stage 0 ) and with neurological disturbances (stages $0_{\mathrm{TN}}$ ).

Table 1 gives the sensitivity and the specificity of three diagnostic criteria to assess VWF by means of the cold provocation test used in this investigation. In the reference group the percentage of recovery of the base-line FST in the cooled finger (T\%) averaged 100 , ie, complete recovery, at about $20 \mathrm{~min}$ following the cold provocation. The lower limit for $\mathrm{T} \%_{20}$ min (mean - 2SD) was found to be $86 \%$ for the referents. Five of the 64 vibration workers without VWF (stages 0 and $0_{\mathrm{TN}}$ ) had a $\mathrm{T} \%_{20 \mathrm{~min}}$ below the lower normal limit (specificity 0.92 ), while 12 of the 20 VWF operators showed abnormal test results (sensitivity 0.60). The measurements of FSP immediately after cooling revealed that zero pressure in the provoked finger, meaning complete closure of the digital arteries, was found in none of the referents, in two of the 64 vibration workers without VWF, and in 14 of the 20 workers with VWF. The sensitivity of the method to detect Raynaud's phenomenon was therefore 0.70 , and the specificity was 0.97 . Among the referents the lower normal limit for FSP\% was 60 . With an FSP $\%$ of $<60$ as the indicator of abnormal cold reactivity in the digital arteries, the sensitivity of the test (hyperreactivity with VWF) increased to 1.00 and the specificity (normoreactivity without VWF) decreased to 0.89 . A good correlation was observed between FSP $\%$ and $\mathrm{T} \%_{20 \text { min }}(\mathrm{r}=0.42, \mathrm{P}<0.001)$.

\section{Conclusions}

FST can provide useful information on digital vascular responsiveness to cold stress in normal subjects and in workers with different stages of VWF. Experimental studies, however, have demonstrated that FST is influenced not only by digital blood flow, but also by individual and environmental factors. Well-controlled test conditions are therefore needed to obtain reproducible results. It is also necessary to standardize the challenge procedure (water temperature, immersion time, body cooling or heating) in order to obtain comparable data from different studies. Skin thermometry after cold exposure can differentiate between VWF groups and healthy groups, but it is unsuitable for diagnosing Raynaud's phenomenon on an individual basis. The thermometric method has a good specificity but its sensitivity is lower than that of other laboratory techniques, as, for instance, digital blood pressure measurement. FST may be considered a useful screening test in field surveys, while more sensitive 
methods should be employed to confirm VWF symptoms objectively, especially for insurance compensation purposes.

\section{Acknowledgments}

The author wishes to thank Dr B Sjovall for his valuable assistance.

\section{References}

1. Bovenzi M, Petronio L, DiMarino F. Epidemiological survey of shipyard workers exposed to hand-arm vibration. Int Arch Occup Environ Health 46 (1980) $251-266$.

2. Chucker R, Fowler RC, Motomiya T, Singh B, Hurley W. Induced temperature transients in Raynaud's disease measured by thermography. Angiology 22 (1971) $580-593$.

3. Cleophas TJM, Fennis JFM, van't Laar A. Finger temperature after a finger-cooling test: Influence of air temperature and smoking. J Appl Physiol Respir Environ Exercise Physiol 52 (1982) $1167-1171$.

4. Greenfield ADM. The circulation through the skin. In: Hamilton WF, ed. Handbook of physiology. Section 2 (Circulation, volume II). American Physiological Society, Washington, DC 1963, pp 1325-1351.

5. Hsieh ACL, Nagasaka T, Carlson LD. Effects of immersion of the hand in cold water on digital blood flow. J Appl Physiol 20 (1965) 61-64.

6. Juul C, Nielsen SL. Locally induced digital vasospasm detected by delayed rewarming in Raynaud's phenomenon of occupational origin. Br J Ind Med 38 (1981) $87-90$.

7. Montgomery LD. Quantitative values of blood flow through the human forearm, hand and finger as functions of temperature. Ames Research Center, Moffett Field, CA 1974. (NASA TM X-62,342).

8. Montgomery LD, Williams BA. Effect of ambient temperature on the thermal profile of the human forearm, hands and fingers. Ann Biomed Eng 4 (1976) 209-219.

9. Okada A, Yamashita T, Nagono C, Ikeda T, Yachi A, Shibata S. Studies on the diagnosis and pathogenesis of Raynaud's phenomenon of occupational origin. $\mathrm{Br} \mathrm{J}$ Ind Med 28 (1971) 353-357.

10. Olsen N, Nielsen SL. Diagnosis of Raynaud's phenomenon in quarrymen's traumatic vasospastic disease. Scand J Work Environ Health 5 (1979) 249-256.

11. Petronio L, Bovenzi M, Fiorito A. Individual factors and peripheral vascular hyperreactivity: A preliminary study on anthropometric data of workers exposed and unexposed to hand-arm vibration. In: Eustace I E, ed. Proceedings of the XXI International Congress on Occupational Health, Dublin Sept 9-14, 1984. Dublin, 1984, p 577.

12. Porter JM, Snider RL, Bardana EJ, Rösch J, Eidemiller LP. The diagnosis and treatment of Raynaud's phenomenon. Surgery 77 (1975) $11-23$.

13. Spurr GB, Hutt BK, Horvath SM. The effects of age on finger temperature responses to local cooling. Am Heart J 50 (1955) $551-555$. 